\title{
STATIC CHARACTERISTICS OF PRESSURE CONTROL VALVE
}

\author{
VYKOUKAL Ondřej ${ }^{1}$, HRUŽÍK Lumír ${ }^{1}$, BUREČEK Adam ${ }^{1}$ \\ ${ }^{I} V \check{B} B$ - Technical University of Ostrava, Faculty of Mechanical Engineering, Department of Hydromechanics \\ and Hydraulic Equipment, 17. listopadu 15, 70833 Ostrava, Czech Republic, email: ondrej.vykoukal@vsb.cz
}

\begin{abstract}
The article deals with the measurement of static characteristics of a pressure control valve. The pressure, at which the valve starts to leak oil, is adjusted by a spring. The measurement is performed on a hydraulic system that consists of tank, hydraulic pump, check valve, relief valve and pressure control valve which is measured. The results of this experimental measurement are $\Delta p-Q$ characteristics of the pressure control valve for various pressure settings.
\end{abstract}

KEYWORDS: Pressure control valve, measurements, static characteristics

\section{Introduction}

The measured valve is conceptually designed as a spool valve. This valve is primarily used to control the geometric volume of the axial piston pump with a swashplate [1]. The geometric volume of the hydraulic pump is set by the pressure behind the hydraulic pump. This pressure pushes on the valve spool which is opposed by a spring force. The valve enables subsequently flow of pressure liquid to the servo cylinder piston. The servo cylinder under pressure inclines the swashplate of the axial piston pump against the spring force of the swashplate. This control is known as pressure compensation. During measurements the function of the pressure compensation valve was modified to function as a relief valve. This measurement is performed in order to verify the mathematical 3D models of flow in the valve.

\section{Functional description of pressure compensation valve}

Simplified section of the measured valve, where the working elements and channels are shown can be seen in Fig. 1. The pressure liquid flows through the channel $\mathrm{P}$ to the spool of the measured valve. This liquid pressure overcomes the force in spring 1 of the pressure compensation valve. The channel A to the servo cylinder SC remains closed. The swashplate of the axial piston pump has the maximum angle of incline and hydraulic pump delivers maximum flow. If the pressure increases over the adjusted value, the spring 1 is compressed and the spool $\mathrm{S}$ is moved. For this reason the flow area between the channel $\mathrm{P}$ and the channel $\mathrm{A}$ is increased. At the same time the flow area between the channels $\mathrm{A}$ and $\mathrm{T}$ is reduced. The pressure liquid pushes on the piston surface of the servo cylinder SC and overcomes the force of spring 2, which inclines the swash plate of the axial piston pump. Then the flow from the hydraulic pump HP is changed. If the system pressure decreases, the spool S is gradually returned to its original position. Simultaneously the flow area between the channels A and T is opened. 


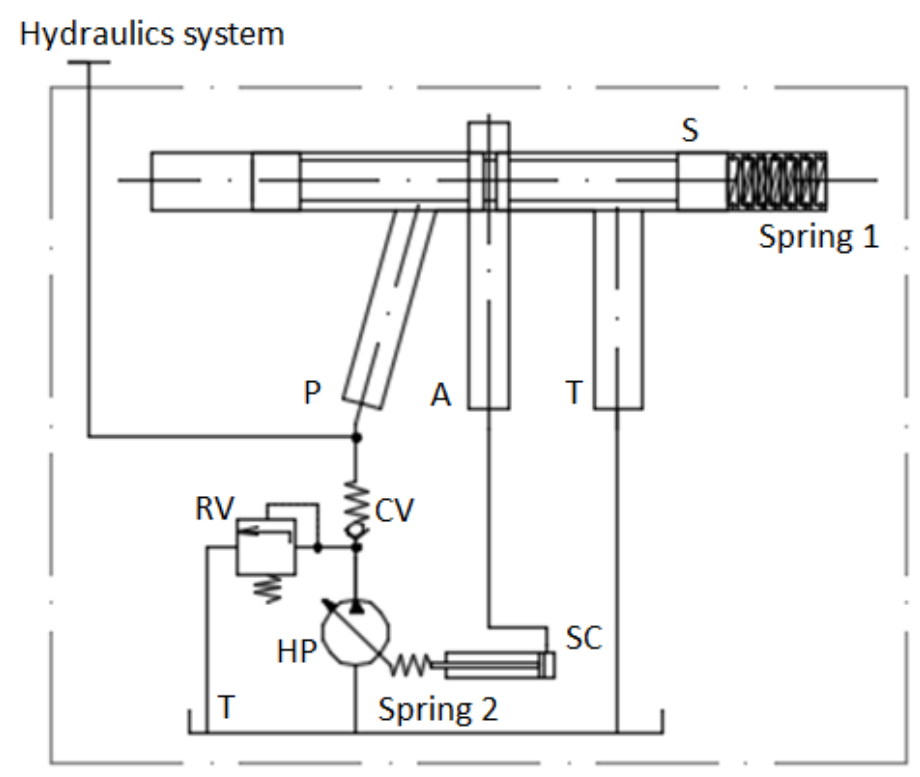

Fig. 1 Simplified valve section

Then the pressure on the servo cylinder will be reduced and the spring 2 ensures the maximum angle of the swash plate. Therefore the flow rate $Q$ is gradually increased to the maximum value [2].

\section{Experiment}

The scheme of the hydraulic system for measurements of static characteristics of the measured valve is shown in Fig. 2.

The specification of elements is as follows:

HP - hydraulic pump PPAR 2-63 10AP, TOS; RV - relief valve ARAM- 20/350, ATOS; $\mathrm{CV}$ - check valve; V - measure valve; T - tank; BV1, BV2 - ball valves; S1, S2 - pressure sensors PR15 Hydrotechnik, accuracy $\pm 0.5 \%$, measuring range $p=(0 \div 400)$ bar, output signal $I=(4 \div 20) \mathrm{mA}$; S3 - gear flow meter QG100 Hydrotechnik, measuring range $Q=(0.05 \div 5) \mathrm{dm}^{3} \cdot \mathrm{min}^{-1}$, accuracy $\pm 0.5 \%$, output signal: frequency; $\mathrm{S} 4$ - gear flow meter QG100 Hydrotechnik, measuring range $Q=(0.7 \div 70) \mathrm{dm}^{3} \cdot \mathrm{min}^{-1}$, accuracy $\pm 0.5 \%$, output signal: frequency; S5, S6 - temperature sensors Pt100 Hydrotechnik, measuring range $t=$ $(-50 \div 200){ }^{\circ} \mathrm{C}$, accuracy $\pm 1 \%$, output signal $I=(4 \div 20) \mathrm{mA}$; MS5060+ - universal measuring device Hydrotechnik.

Description of measurement:

The hydraulic pump HP delivers oil from the tank T through the check valve CV to the input of the measured valve $\mathrm{V}$. Oil flows from the inlet channel $\mathrm{P}$ to the outlet channel $\mathrm{A}$ through the throttle edge in the measured valve V. Oil flows subsequently from the outlet channel A of the valve $\mathrm{V}$ through gear flowmeter S3 or S4 to the tank T. The pressure sensor $\mathrm{S} 1$ is connected to the inlet channel $\mathrm{P}$ of the measured valve $\mathrm{V}$. The pressure sensor $\mathrm{S} 2$ is connected to the outlet channel $\mathrm{A}$ of the measured valve $\mathrm{V}$. The pressure drop between channels $\mathrm{P}$ and $\mathrm{A}$ is given by the difference between the pressures $p_{1}$ and $p_{2}$. There are connected in parallel two gear flowmeters S3 and S4 for different measuring ranges and temperature sensors S5 and S6 in the system. The flowmeter S3 or S4 is connected by means of valve BV1 or BV2. Measured values from sensors are recorded by the measuring device MS5060+. The oil flows subsequently from the gear flowmeter to the tank T. There was used 
the oil of VG 46 type with density $\rho=868 \mathrm{~kg} \cdot \mathrm{m}^{-3}$, the temperature $t=40^{\circ} \mathrm{C}$ and the kinematic viscosity $v=47.5 \mathrm{~mm}^{2} \cdot \mathrm{s}^{-1}$ in this case.

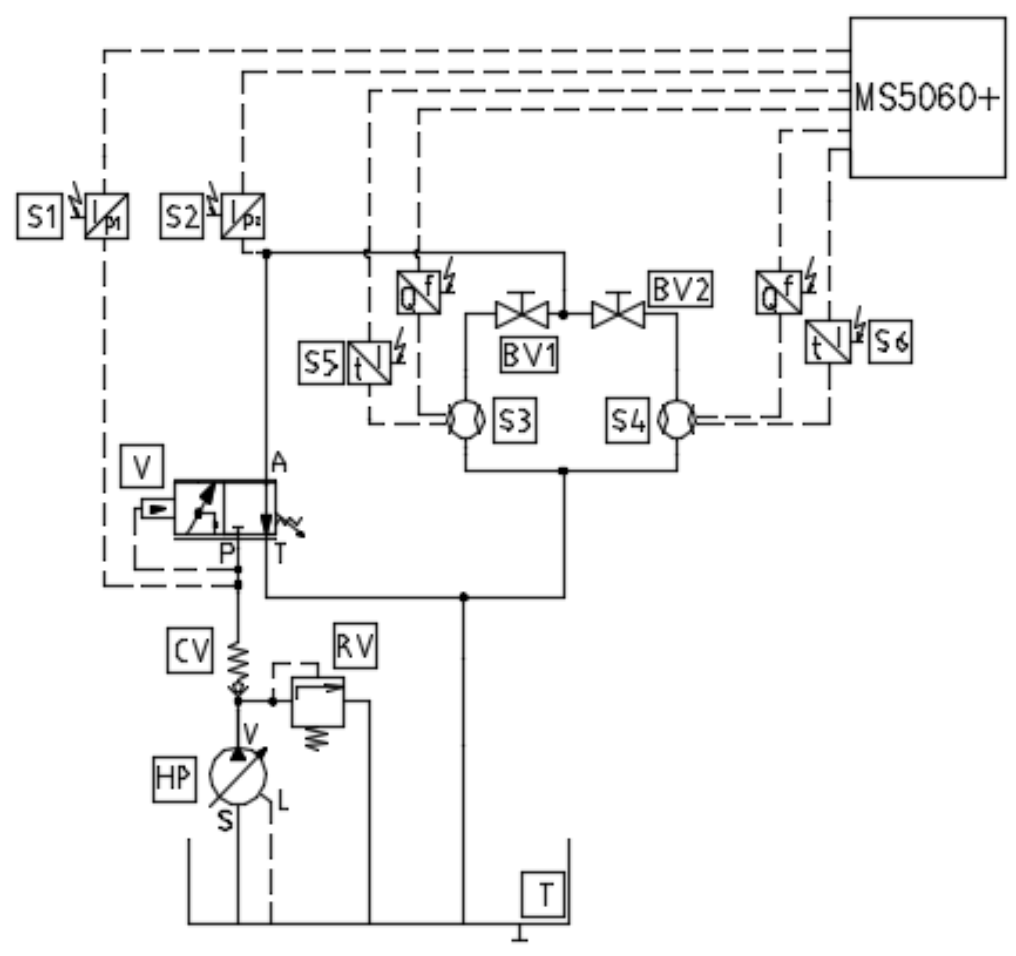

Fig. 2 Scheme of measuring equipment

View of the main part of the measured system is shown in Fig. 3. The hydraulic pump HP was adjusted with the geometric volume $V_{G}=13 \mathrm{~cm}^{3}$.

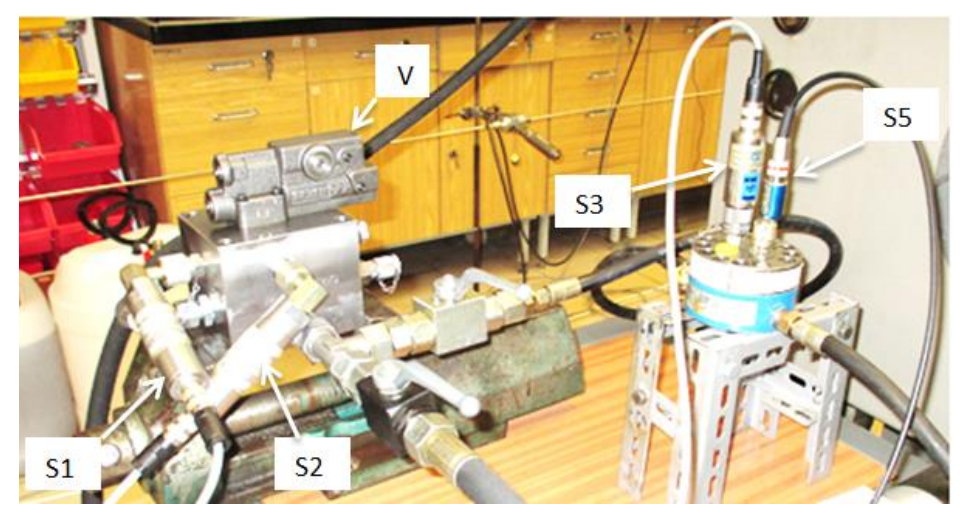

Fig. 3 The connection of sensors

It was performed measurement of the pressure drop $\Delta p$ between the channels $\mathrm{P}$ and $\mathrm{A}$ depending on the flow rate $Q$ of the measured valve $\mathrm{V}$. Measurements are performed for different pressures $p_{1}$, at which occurs the beginning of opening of the flow area between the channels $\mathrm{P}$ and $\mathrm{A}$. The magnitude of the opening pressure $p_{1}$ was given by the spring 1 preload of the measured valve $\mathrm{V}$. The spring 1 preload was adjusted for the valve initial opening pressure $p_{1}=(30,60,90,120,150)$ bar. Measurement was performed at the oil temperature $t=(50 \pm 3){ }^{\circ} \mathrm{C}$ [3]. If the pressure $p_{1}$ increases over the adjusted value of the spring 1 force, than the flow area between the channels $\mathrm{P}$ and A begins to increase. For this reason the flow rate $Q$ through this cross-section is increased. The pressure $p_{1}$ is gradually increased till than the flow rate $Q$ doesn't increase further. It means that the flow area between the channels $\mathrm{P}$ and $\mathrm{A}$ is maximal. This procedure is repeated for each initial opening pressure 
$p_{1}$. The dependencies of the pressure drop $\Delta p$ on the flow rate $Q$ for the measured valve $\mathrm{V}$ were evaluated from measured data.

\section{$4 \quad$ Evaluation of measurements}

Fig. 4 shows the dependencies of pressure drop $\Delta p$ on the flow rate $Q$ of the measured valve $\mathrm{V}$ for initial opening pressure $p_{1}=(30,60,90,120,150)$ bar.

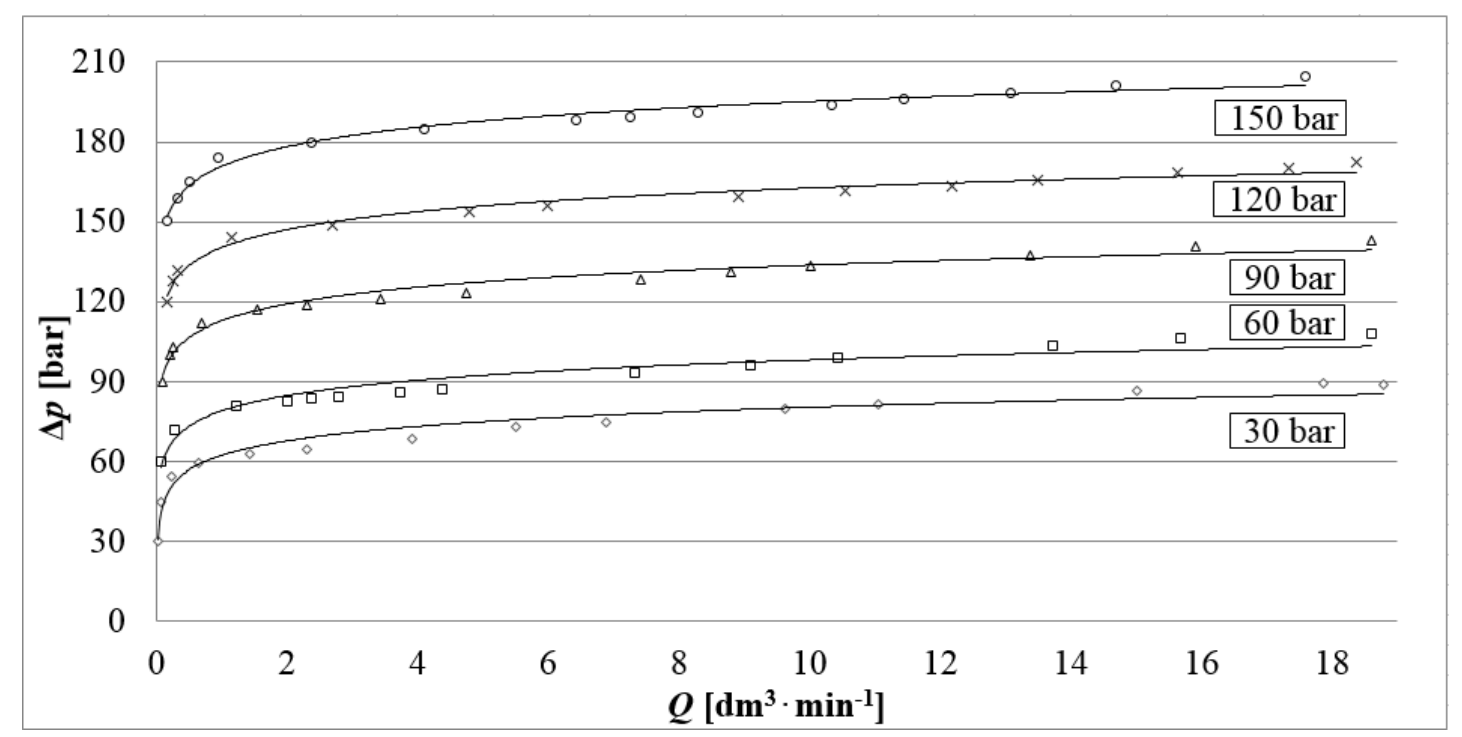

Fig. 4 Dependencies of the pressure drop $\Delta p$ on the flow rate $Q$ of the measured valve for initial opening pressure $p_{1}=(30,60,90,120,150)$ bar

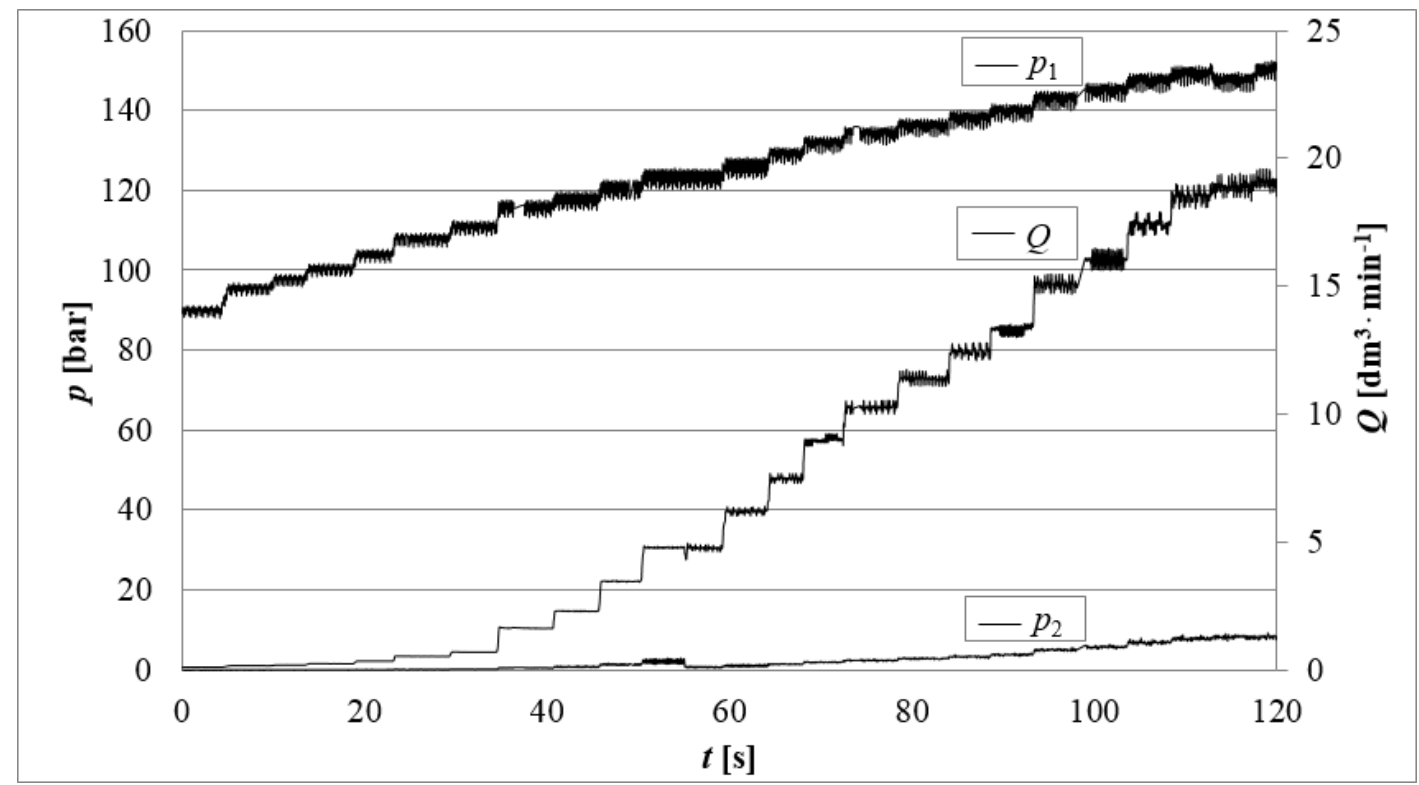

Fig. 5 Record of measurements for the initial opening pressure $p_{1}=90 \mathrm{bar}$

The initial opening pressures $p_{1}$ at the flow rate $Q=0 \mathrm{dm}^{3} \cdot \mathrm{min}^{-1}$ are evident in Fig. 4. The flow rate $Q$ increases slowly with the increasing pressure drop $\Delta p$ at the process beginning. The pressure values $p_{1}$ were increased gradually by means of the relief valve RV. For this reason the flow rate $Q$ was increased. The flow area between the channels $\mathrm{P}$ and $\mathrm{A}$ is gradually increases. Then, during a further increase of pressure drop $\Delta p$, the flow rate $Q$ increases faster. It is subsequently seen (see Fig. 4) that the dependence of the pressure drop $\Delta p$ on the flow rate $Q$ is almost linear in this case. This is given by the geometry of the 
measured valve and the stiffness of the spring 1. At the beginning of opening the valve may occur cavitation [4].

Fig. 5 shows the measured time dependencies of pressures $p_{1}$ and $p_{2}$ and the flow rate $Q$ during the initial opening pressure setting $p_{1}=90 \mathrm{bar}$.

\section{Conclusion}

The article deals with the measurement of static characteristics of a pressure compensation valve. The dependence of the pressure drop on the flow rate is measured. Firstly the flow rate increases slowly with increasing pressure drop at very low flow rates. Then, during further increase in pressure drop, there is a greater increase of flow rate. In this case the dependence of the pressure drop on the flow rate is almost linear. This measurement will be used in order to verify the mathematical 3D models of flow in the valve.

\section{ACKNOWLEDGEMET}

The work presented in this paper was supported by a grant SGS „Výzkum v oblasti dynamiky tekutinových systémů." SP2017/103.

\section{REFERENCES}

[1] H. Exner, R. Freitag, et al. Hydraulics. Basic Principles and Component, Bosch Rexroth AG, 2002. 326 p. ISBN 3-933698-32-4.

[2] F. Bušo, Diplomová práce Matematické 3D modelování proudění oleje v šoupátkovém ventilu tlakové regulace. Ostrava: VŠB- TU Ostrava 2015. 54 p.

[3] Hydrotechnik GmbH, (Catalogue Papers).

[4] Z. Csuka, R. Olšiak, Z. Fuszko, Research of Cavitation at High Shear Stress. Journal of Mechanical Engineering - Strojnícky časopis, 2016 (66), No. 1, 7 - 16. ISSN 24505471. 
